\title{
COMPETÊNCIAS DIGITAIS DE DOCENTES UNIVERSITÁRIOS EM TEMPOS DE PANDEMIA: ANÁLISE DA AUTOAVALIAÇÃO DIGCOMPEDU
}

\author{
PROFESSOR'S DIGITAL COMPETENCES IN PANDEMIC TIMES: DIGCOMPEDU \\ SELF-ASSESSMENT ANALYSIS \\ COMPETENCIAS DIGITALES DE LOS PROFESORES UNIVERSITARIOS EN \\ TIEMPOS DE PANDEMIA: ANÁLISIS DE AUTOEVALUACIÓN DIGCOMPEDU
}

\author{
Sara Dias-Trindade \\ Universidade de Coimbra - Portugal
}

Eniel do Espírito Santo

Universidade Federal do Recôncavo da Bahia - Brasil

\begin{abstract}
Resumo: O uso de tecnologias digitais em ambientes educativos tem vindo a ser discutido nos últimos anos, dando destaque à necessidade de formação adequada para que este uso proporcione uma efetiva melhoria dos processos educativos e potencie as aprendizagens dos estudantes. Quando a pandemia da Covid-19 obrigou as instituições de ensino a encerrar as portas físicas, o projeto que se apresenta neste trabalho encontrava-se em curso e tinha por objetivo avaliar o nível de competências digitais dos docentes da Universidade Federal Recôncavo da Bahia (UFRB), a partir do questionário de autoavaliação DigCompEdu, validado por Dias-Trindade, Moreira e Nunes (2019), para de seguida organizar formação docente adequada ao suprimento das necessidades verificadas no corpo docente daquela instituição. A pandemia, e a consequente necessidade de aposta num ensino digital de qualidade acelerou o trabalho do projeto em curso, para que a referida formação fosse preparada e adequada às necessidades decorrentes da continuidade de um ensino completamente a distância. Os resultados deste estudo mostraram as fragilidades dos 182 docentes respondentes, em particular na área da avaliação da aprendizagem, levando à preparação de formação docente que se encontra já em fase de implementação na UFRB.
\end{abstract}

Palavras chave: Competências digitais; COVID-19; DigCompEdu.

\begin{abstract}
The use of digital technologies in educational environments has been largely discussed in recent years, highlighting the need for adequate training so that its use can provide an effective improvement of educational processes and enhance student learning. When the Covid-19 pandemic forced educational institutions to close their physical doors, the research presented in this work was in progress and aimed to assess the level of digital skills of teachers at the Federal University of Bahia's Recôncavo (UFRB), based on the DigCompEdu self-assessment tool, validated by Dias-Trindade, Moreira and Nunes (2019), to subsequently organize adequate teacher training to meet the needs of the teaching staff of that institution. The pandemic, and the consequent need to invest in quality digital education, accelerated the project's work, and the referred training was duly prepared and adapted to the needs arising from the continuity of distance education. The results of this study showed the weaknesses of the 182 respondent teachers, particularly in the area of learning assessment, leading to the teacher training preparation, already being implemented at UFRB.
\end{abstract}

Keywords: Digital Competences; COVID19; DigCompEdu. 
Resumen: El uso de tecnologías digitales en entornos educativos ha sido ampliamente discutido en los últimos años, destacando la necesidad de una formación adecuada para que su uso pueda proporcionar una mejora efectiva de los procesos educativos y potenciar el aprendizaje de los estudiantes. Cuando la pandemia Covid-19 obligó a las instituciones educativas a cerrar sus puertas físicas, la investigación presentada en este trabajo estaba en progreso y tenía como objetivo evaluar el nivel de competencias digitales de los docentes de la Universidad Federal del Recôncavo da Bahia (UFRB), con base en la herramienta de autoevaluación DigCompEdu, validada por Dias-Trindade, Moreira y Nunes (2019), para posteriormente organizar una formación docente adecuada a las necesidades del profesorado de esa institución. La pandemia, y la consecuente necesidad de invertir en educación digital de calidad, aceleró el trabajo del proyecto, y la referida capacitación fue debidamente preparada y adaptada a las necesidades derivadas de la continuidad de la educación a distancia. Los resultados de este estudio evidenciaron las debilidades de los 182 docentes encuestados, particularmente en el área de evaluación de aprendizajes, que llevaron a la preparación de formación docente, que ya se está implementando en la UFRB.

Palabras clave: Competencias Digitales; COVID19; DigCompEdu.

\section{Introdução}

O isolamento social resultante da pandemia Covid-19 impulsionou as instituições de ensino na busca de alternativas analógicas e digitais a fim de continuar os processos de ensino e aprendizagem em tais condições adversas. Deveras, o ciberespaço com o seu ecossistema de cenários e ambientes virtuais de aprendizagem tem possibilitado a continuidade de estudos, não obstante a falta de acesso à rede de internet ou seu uso tão somente por celular nos extratos da população de baixa renda, cujas tímidas políticas públicas de inclusão digital necessitam de aperfeiçoamento para se evitar a ampliação do vergonhoso fosso da desigualdade social, especialmente nos países pobres e em desenvolvimento.

No contexto do Brasil, a internet está presente em $71 \%$ (setenta e um por cento) dos domicílios conforme revelou a pesquisa TIC Domicílios 2019 do Comitê Gestor da Internet (CGI, 2020), apontando elevado nível de desigualdade regional: por exemplo, na região Nordeste somente $35 \%$ dos domicílios possuem acesso à rede. Por outro lado, de acordo com tais dados, em média 3 (três) em cada 4 (quatro) brasileiros utilizam a internet, fornecendo subsídios para que as instituições de ensino retomassem suas atividades durante a pandemia da Covid-19, utilizando o ensino remoto online. Os professores foram arremessados para os ambientes virtuais, com um processo formativo aligeirado e amiúde meramente instrumental ou, na maioria das vezes, sem nenhuma formação capaz de lhes proporcionar o desenvolvimento ou aprimoramento das competências digitais demandadas pelos espaços virtuais. 
Entretanto, a necessidade do desenvolvimento de competências digitais dos professores não é algo que emergiu no contexto da pandemia Covid-19, pois a crescente ampliação da banda larga de internet e dos dispositivos móveis têm impulsionado uma sociedade cada vez mais hiperconectada e em rede, demandando soluções inovadoras no campo da educação. De fato, a Agenda 2030 proposta pela ONU estabelece os 17 Objetivos de Desenvolvimento Sustentável, destacando-se no 4o. objetivo a premente necessidade de se aumentar o contingente de professores qualificados por meio de programas de formação de professores (ONU, 2015).

Neste contexto de pandemia que demanda ação docente mais assertiva possível, este estudo tem por objetivo analisar o nível das competências digitais de professores do magistério público superior, vinculados à Universidade Federal do Recôncavo da Bahia (UFRB), visando o mapeamento do nível das competências em que se encontram e a proposição de possibilidades para que galguem os níveis mais elevados de competências e fluência digital demandados.

Este estudo configura-se como uma pesquisa exploratória e descritiva, com abordagem quantitativa, tendo como procedimentos de coleta de dados a pesquisa de levantamento com 182 docentes universitários, por meio do questionário DigCompEdu - UFRB Autoavaliação das Competências Digitais dos Professores, acessado pela plataforma online EU Survey.

\section{Competências Digitais Docentes}

A práxis docente nesta desafiadora modernidade líquida (BAUMAN, 2001) demanda dos professores o contínuo desenvolvimento de competências relacionadas com o chamado conhecimento tecnológico e pedagógico do conteúdo (TPACK $)^{1}$, isto é, além de considerar o contexto socioeconômico e político das situações de aprendizagem, também é preciso atentar para que o processo de ensino dos conteúdos curriculares contemplem, sobretudo, técnicas pedagógicas e estratégias didáticas ancoradas na utilização de tecnologias digitais emergentes, como apontam Koehler, Mishra e Cain (2013) e Santo e Cardoso (2020).

Se, antes da pandemia Covid-19, o conhecimento tecnológico do conteúdo demandava o desenvolvimento das competências digitais dos professores, tanto mais agora que o isolamento social e as medidas sanitárias arremessaram os processos de ensino para os ambientes virtuais de aprendizagem como nunca antes observado. Neste sentido, apesar de ser um construto de difícil definição (BOTERF, 2005), compreendemos competência digital na perspectiva de Sales e Moreira (2019, p. 18), ao afirmarem que,

[...] competência digital é o exercício sensorial, cognitivo, motor e afetivo das habilidades, valores, conhecimentos, informações, experiências dos sujeitos nas práticas de conhecimento, reconhecimento e uso das TIC digitais e

\footnotetext{
${ }^{1}$ Do inglês Technological Pedagogical Content Knowledge
} 
conectadas, no sentido de tomar decisões, atitudes e agir de modo autônomo nos processos de intervenção, mediação e resolução de problemas oriundos do contexto da sociedade da aprendizagem, possibilitando a transformação, mudança social, política e econômica nos diversos cotidianos e setores da sociedade, inclusive na educação.

Desta forma, as competências digitais englobam a capacidade de trabalho docente efetivo nos ambientes digitais, articulado com as especificidades que tais espaços demandam ao fazer pedagógico. Tais competências digitais são evidenciadas na capacidade do professor em "mobilizar conhecimentos e atitudes para um uso efetivo da tecnologia digital" na sua prática educativa, facilitando o processo de ensino e aprendizagem e contribuindo "para potenciar o desenvolvimento destas mesmas competências digitais nos estudantes", no dizer de Dias-Trindade e Ferreira (2020, p. 169-170).

Destarte, a pandemia Covid-19 explicitou a necessidade de os professores possuírem competências digitais capazes de embasar a sua práxis pedagógica nos ambientes virtuais de aprendizagem em consonância com uma sociedade digital e com estudantes, em sua maioria, hiperconectados, qual geração de polegarzinhas e polegarzinhos, no dizer de Serres (2015).

Deveras, a utilização das tecnologias digitais integradas em um desenho didático pedagógico que contemple a utilização de ecossistemas digitais de aprendizagem possibilita, sobretudo, aproveitar as potencialidades das tecnologias no processo de ensino e aprendizagem, tornando-o motivador, dinâmico e fomentador de aprendizagens complexas (EUROPEAN PARLIAMENT AND COUNCIL, 2006; ILOMÄKI; PAAVOLA; LAKKAKA; KANTOSALO, 2016; INTEF, 2017; DIAS-TRINDADE; MOREIRA, 2018).

Não restam dúvidas das potencialidades pedagógicas advindas das Tecnologias Digitais da Informação e Comunicação (TDIC) que tornaram possível em tempos de pandemia a continuidade dos processos educacionais. Todavia, frente ao cenário desafiador, é imperioso que os docentes conheçam o nível de suas competências digitais para que sejam capazes de implementar melhorias em sua prática educativa, ressaltam Ota e Dias-Trindade (2020).

Desta forma, não se trata de mera transposição didática das metodologias utilizadas na modalidade presencial para o ensino online, mas do desenvolvimento de competências docentes que os habilitem a utilizar as tecnologias digitais na promoção da emancipação dos estudantes, isto é, proporcionando um sentimento de pertencimento dos alunos e desejo de participação na construção do conhecimento, contribuindo para uma ação efetiva tanto na comunidade acadêmica quanto no mundo do trabalho (FERRARI, 2012; FIGUEIREDO, 2016; FROM, 2017; RANIERI; BRUNI; XIVRY, 2017). Neste contexto, é oportuno afirmar o desafio contemporâneo é saber utilizar as tecnologias "para transformar a aprendizagem num ato 
normal do quotidiano, até mesmo fazendo com que esta nem seja sequer reconhecida como sendo aprendizagem" (DIAS-TRINDADE; MOREIRA, 2017, p. 54).

No bojo das discussões para o desenvolvimento e aprimoramento das competências digitais dos professores, no Brasil o Centro de Inovação para a Educação Brasileira (CIEB) desenvolveu uma Matriz de Competências Digitais CIEB que consiste em uma autoavaliação dos professores em 3 (três) áreas distintas, isto é, pedagógica, cidadania digital e desenvolvimento profissional, visando subsidiar o desenvolvimento das competências digitais dos professores (SALES; MOREIRA, 2019).

Na Europa, o Serviço de Ciência e Conhecimento da Comissão Europeia ${ }^{2}$ lançou o DigCompEdu, um quadro comum para competências digitais dos professores em 2017, tendo em vista as especificidades do fazer docente diante do potencial das TDIC no processo de ensino e aprendizagem (REDECKER, 2017). Trata-se do modelo teórico que fundamenta este estudo, considerando-se que o DigCompEdu contou com a colaboração de pesquisadores oriundos de diversos países amparados em um suporte epistêmico que reflete as discussões efervescentes deste campo de estudos.

O EU Science Hub estruturou um questionário para a autoavaliação dos professores com o objetivo de identificar o nível de competência digital em que os docentes se encontram, fornecendo-lhes devolutivas com sugestões para a melhoria de seu fazer pedagógico com a utilização das tecnologias digitais. No Quadro 1, observamos as 6 (seis) áreas de competências que constituem o DigCompEdu, abarcando-se o mapeamento das competências digitais específicas relacionadas à sua área do conhecimento; competências profissionais; competências pedagógicas e o desenvolvimento das competências dos estudantes.

\section{Quadro 1: Áreas de competência do DigCompEdu}

\begin{tabular}{|l|l|}
\hline Áreas de Competência Digital & \multicolumn{1}{c|}{ Descrição } \\
\hline Envolvimento profissional & $\begin{array}{l}\text { Utilização das tecnologias digitais para selecionar, criar e partilhar recursos } \\
\text { digitais. }\end{array}$ \\
\hline Tecnologias e recursos digitais & $\begin{array}{l}\text { Utilização das tecnologias digitais para comunicar, colaborar e promoção do } \\
\text { desenvolvimento profissional. }\end{array}$ \\
\hline Ensino e aprendizagem & $\begin{array}{l}\text { Capacidade para gerir e organizar o uso de tecnologias digitais nas diversas } \\
\text { facetas do processo de ensino e aprendizagem }\end{array}$ \\
\hline Avaliação & $\begin{array}{l}\text { Utilização das tecnologias digitais para avaliação da aprendizagem e/ou } \\
\text { melhorar os processos avaliativos. }\end{array}$ \\
\hline Formação dos estudantes & $\begin{array}{l}\text { Utilização das tecnologias digitais para melhorar a inclusão, personalização e o } \\
\text { engajamento dos estudantes. }\end{array}$ \\
\hline $\begin{array}{l}\text { Promoção das competências } \\
\text { digitais dos estudantes }\end{array}$ & $\begin{array}{l}\text { Orientação e subsídios aos estudantes no uso das tecnologias digitais de forma } \\
\text { criativa e responsável. }\end{array}$ \\
\hline Fonte: Adaptado de Ota Dias-Tring \\
\hline
\end{tabular}

Fonte: Adaptado de Ota e Dias-Trindade (2020). 
No questionário de autoavaliação preconizado pelo modelo DigCompEdu, com base em suas respostas, os professores são enquadrados em um dos 6 (seis) níveis que refletem o seu estágio de competências digitais, conforme demonstrado no Quadro 2:

Quadro 2: Níveis de competências digitais do modelo DigCompEdu

\begin{tabular}{|l|l|}
\hline Nível de Competência & \multicolumn{1}{c|}{ Perfill } \\
\hline A1 - Recém-chegado & $\begin{array}{l}\text { Assimilam novas informações e desenvolvem práticas digitais básicas no seu } \\
\text { fazer pedagógico. }\end{array}$ \\
\hline A2 - Explorador & $\begin{array}{l}\text { Aplicam, expandem e refletem criticamente em suas práticas pedagógicas com } \\
\text { a utilização das TDIC. }\end{array}$ \\
\hline B1 - Integrador & $\begin{array}{l}\text { Compartilham seus conhecimentos, refletem criticamente e desenvolvem } \\
\text { novas práticas com as tecnologias digitais. }\end{array}$ \\
\hline C1 - Líder &
\end{tabular}

Fonte: Os autores, 2021.

Perceb-se a relevância da autoavaliação possibilitada pelo modelo DigCompEdu, pois muito além de mapear o nível de competência digital do professor, ele também fornece devolutivas para que o professor seja capaz de avançar para os níveis subsequentes, rumo à fluência digital. Ademais, visto que o questionário permite verificar níveis para cada uma das áreas de competência, pode-se aferir que tipo de formação será mais adequada para cada professor, ou seja, quais as áreas em que precisa se dedicar em sua formação continuada, bem como aquelas em que se encontra mais próximo de um nível de fluência, apontam DiasTrindade e Ferreira (2020).

\section{Caminhos metodológicos do estudo}

Este estudo contempla uma abordagem quantitativa. Para a definição da tipologia de operacionalização, adotaram-se os conceitos de Gil (2007) e Triviños (2006), classificando-o como um estudo exploratório e descritivo que utiliza como procedimento de coleta de dados uma pesquisa de levantamento no formato de um questionário, acessado por meio da plataforma digital EU Survey, configurada no âmbito da Rede Colaborativa de Aprendizagem (RCA).

O questionário utilizado constituiu-se na versão brasileira da escala DigCompEdu CheckIn, proposta por Sales e Santo (2019), contemplando as expressões das TDIC comumente utilizadas no Brasil, visando promover melhor compreensão aos participantes do estudo. Destaca-se que a escala foi desenvolvida originalmente pelo $E U$ Science $H u b$ e validada para a língua portuguesa por Dias-Trindade, Moreira e Nunes (2019). Composto por 21 (vinte e uma) questões, é uma ferramenta de autoavaliação, contemplando um modelo de competências para professores de todos os níveis de ensino, da Educação Infantil ao Ensino Superior, em que as competências digitais docentes são subdivididas em 6 (seis) áreas diferentes.

O DigCompEdu apresenta uma pontuação máxima de 84 pontos, numa escala de 6 (seis) níveis de competências, conforme demonstrado no Quadro 3. 
Quadro 3: Níveis de competências digitais do modelo DigCompEdu

\begin{tabular}{|c|c|}
\hline Nível de Competência & Pontuação \\
\hline A1 - Recém chegado & até 18 pontos \\
\hline A2 - Explorador & entre 19 e 32 pontos \\
\hline B1 - Integrador & entre 33 e 47 pontos \\
\hline B 2 - Especialista & entre 48 e 62 pontos \\
\hline C1 - Líder & entre 63 e 77 pontos \\
\hline C2 - Pioneiro & mais de 77 pontos \\
\hline
\end{tabular}

Fonte: $\mathrm{O}$ autores, 2021

Dias-Trindade, Moreira e Nunes (2019) efetuaram a análise da consistência interna do instrumento, por meio do cálculo do coeficiente alfa de Cronbach e a análise da validade do construto (análise fatorial exploratória e confirmatória), revelando indicadores de consistência internos plenamente satisfatórios.

O questionário online foi aplicado entre março e maio de 2020, contando com um universo de 907 docentes da Universidade Federal do Recôncavo da Bahia (UFRB), sendo que se obteve $182(20,1 \%)$ respostas válidas que integram a amostra desta pesquisa.

Com o objetivo de atender às resoluções do Conselho Nacional de Ética em Pesquisa (CONEP) que regulam as pesquisas científicas com participantes humanos no Brasil, o projeto de pesquisa foi previamente submetido e aprovado por um Comitê de Ética em Pesquisa (CEP), com o parecer n. 3.582.41.

\section{Apresentação e discussão dos resultados}

A amostra de 182 professores participantes apresenta-se bastante equitativa no que diz respeito ao gênero, com 45,6\% (83) de docentes do sexo masculino e 54,4\% (99) do sexo feminino, com uma idade média de 45,5 anos, sendo 25 anos a idade mínima e 66 a idade máxima. A distribuição por área de atuação mostra uma superioridade de professores da área das Ciências Exatas e da Terra (22\%), logo seguida da área das Ciências Humanas (19,8\%). A área de atuação com menor representação é a das Ciências Biológicas, representando apenas $3,9 \%$ da nossa amostra. (Tabela 1).

Tabela 1: Áreas de atuação dos docentes participantes da amostra.

\begin{tabular}{l|c|c}
\multicolumn{1}{c|}{ Área de atuação } & Participantes (n) & \% \\
\hline Ciências Agrárias & 17 & 9,3 \\
\hline Ciências Biológicas & 7 & 3,8 \\
\hline Ciências da Saúde & 20 & 11,0 \\
\hline Ciências Exatas e da Terra & 40 & 22,0 \\
\hline Ciências Humanas & 36 & 19,8 \\
\hline Ciências Sociais Aplicadas & 14 & 7,7 \\
\hline Engenharias & 22 & 12,1 \\
\hline Linguística, Letras e Artes & 26 & 14,3
\end{tabular}

Fonte: Os autores, 2021. 
O resultado médio deste estudo é de 41 pontos, ou seja, colocando este grupo de participantes a meio do nível B1 - Integrador. Este nível agrega todos aqueles que já utilizam tecnologias digitais nas suas práticas, têm vontade e curiosidade de aprender mais, porém, precisam de fato de mais formação para poderem evoluir e usar de uma forma mais integrada estes recursos para potenciar as diferentes vertentes do processo educativo.

\section{Gráfico 1 - Valores médios dos itens de competências digitais do questionário}

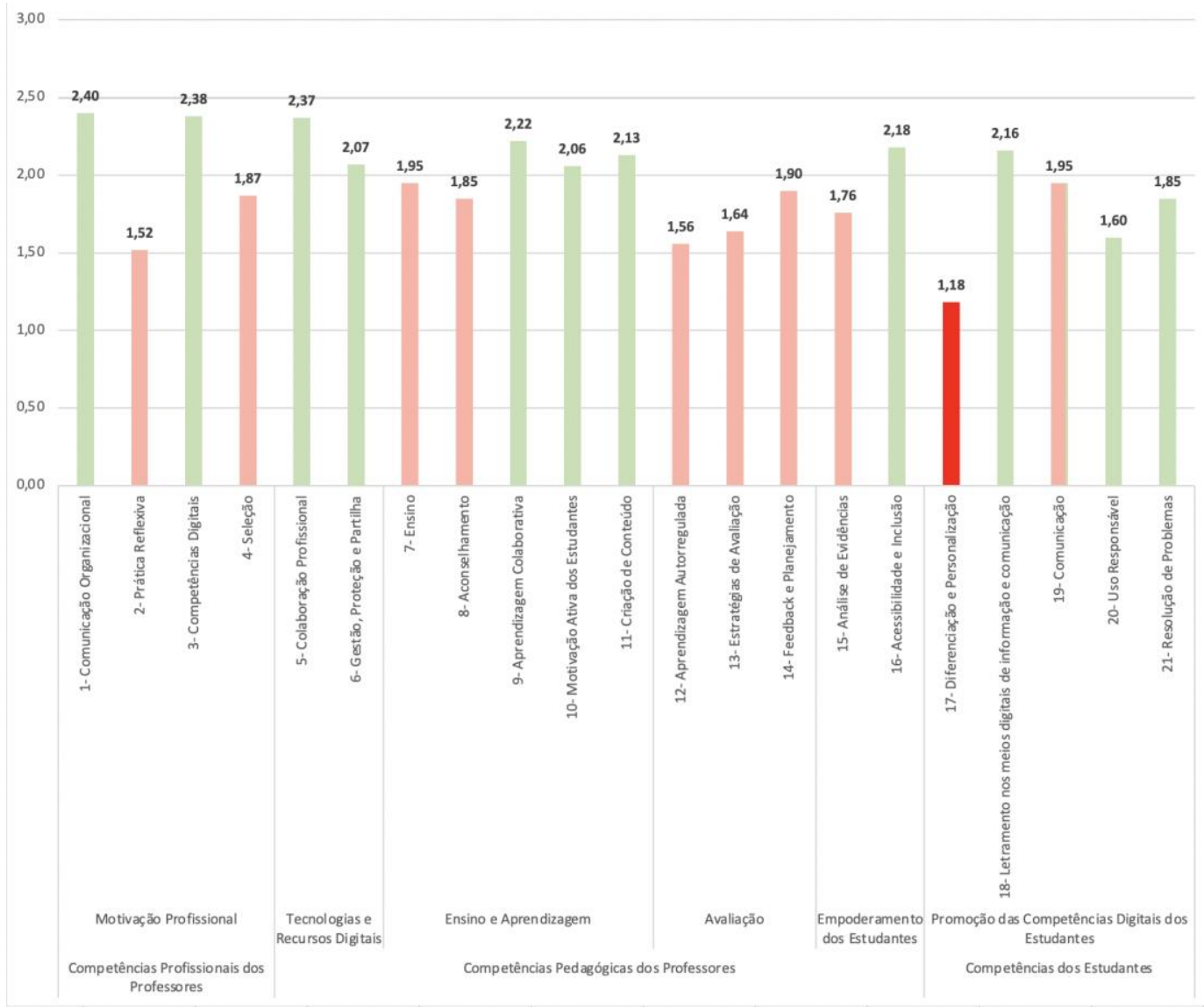

Fonte: Os autores, 2021.

Analisando em particular os resultados médios em cada uma das 21 competências que compõem o instrumento (Gráfico 1), verifica-se que a área com maiores fragilidades é a Área 4 - Avaliação -, apresentando valores médios sempre inferiores a 2 pontos (de um máximo de 4 pontos) e um valor médio que se situa ainda ao nível A2, ainda que muito próximo já do nível seguinte. Por outro lado, a Área 3 - Ensino e Aprendizagem - apesar de alguns valores mais fracos, apresenta o melhor resultado global, integrado no nível B1.

Comparando com os estudos já realizados a partir do mesmo instrumento e com docentes do ensino superior quer no Brasil por Ota e Dias-Trindade (2020), quer em Portugal Dias-Trindade, Moreira e Ferreira (2020), verifica-se a importância que este tipo de trabalho tem na identificação do nível de competências digitais de um dado conjunto de docentes, para 
se conseguir, a partir dessa verificação, atuar de uma forma mais criteriosa e direcionada para as suas reais necessidades. Quando comparados os três estudos, verifica-se uma convergência no nível global dos resultados, todos claramente inseridos no nível B1 - Integrador. Porém, quando analisado em detalhe quer o resultado médio de cada área quer o de cada um dos 21 itens de competências, as diferenças surgem. No estudo de Ota e Dias-Trindade (2020), a área que apresenta maior fragilidade é a área 2 - Tecnologias e Recursos Digitais -, enquanto no estudo de Dias-Trindade, Moreira e Ferreira (2020) essa é a área que tem melhores resultados. Já no presente estudo, é também uma das áreas em que os resultados são mais elevados.

Um aspeto importante na comparação destes resultados é que também o estudo de Ota e Dias-Trindade (2020) foi realizado imediatamente antes do início da pandemia COVID-19, ou seja, ligeiramente antes do estudo que aqui se apresenta. Isto indica que se encontram nestes dois trabalhos dois retratos, contemporâneos, de duas regiões diferentes no Brasil, Sudeste e Nordeste e, concretamente, de duas Instituições de Ensino Superior (IES) brasileiras

Analisando no Gráfico 1 em particular cada um dos itens de competências com a amostra dos professores da UFRB, os que apresentam valores médios mais elevados são:

- Área 1 (competência 1) - Comunicação organizacional - 2,40 pontos;

- Área 1 (competência 3) - Competências digitais - 2,38 pontos;

- Área 2 (competência 5) - Colaboração profissional - 2,37 pontos.

Estes resultados acompanham a definição de Redecker (2017) para o nível B1 que indica que estes docentes integram as competências digitais em diferentes momentos das suas práticas, usando tecnologias digitais para comunicar, colaborar e evoluir profissionalmente.

Porém, os valores mais baixos, que a seguir se enunciam, demonstram que os docentes "precisam de um pouco mais de tempo para experimentar e refletir, complementado com apoio colaborativo e partilha de conhecimentos, para se tornarem Especialistas (B2)" (REDECKER, 2017, p. 30). Estes valores correspondem aos itens de competências evidenciadas no Gráfico 1:

- Área 1 (competência 2) - Prática reflexiva - 1,52 pontos;

- Área 4 (competência 12) - Aprendizagem autorregulada - 1,56 pontos;

- Área 6 (competência 17) - Diferenciação e personalização - 1,18 pontos.

No item de competência 2, o resultado demonstra a importância deste documento para a evolução do professor do letramento para a fluência digital. A importância de este questionário facultar, no final do seu preenchimento, um feedback sobre como proceder para melhorar os seus resultados, torna-se fundamental na promoção de uma prática reflexiva, de um momento em que o docente autoavalia o que entende serem as suas competências digitais e é levado a perceber como pode proceder para melhorar essas mesmas competências. 
Os dois itens de competências com resultados mais frágeis vinculam-se à capacidade de adaptação das práticas docentes às necessidades dos estudantes, quer ao nível da avaliação (a Área 4 - Avaliação - apresenta níveis médios bastante baixos), quer de sua capacitação para o uso do digital, promovendo sobretudo a inclusão e o engajamento desses estudantes.

Analisados os resultados que permitem traçar o perfil de competências digitais docentes no início da pandemia - para preparar formação adequada quer, no período de distanciamento social que o mundo vive, quer num período pós-pandemia, que se supõe vá sofrer mudanças fruto do que hoje vem sendo a relação entre educação e o mundo digital -, importa compreender também se existem fatores que possam, ou não, determinar a maior ou menor capacitação para o uso do digital em ambientes educativos e ainda compreender as especificidades existentes na instituição que participou deste estudo para melhor determinar as ações a desenvolver.

\section{Gráfico 2 - valores médios de competências digitais docentes por idade}

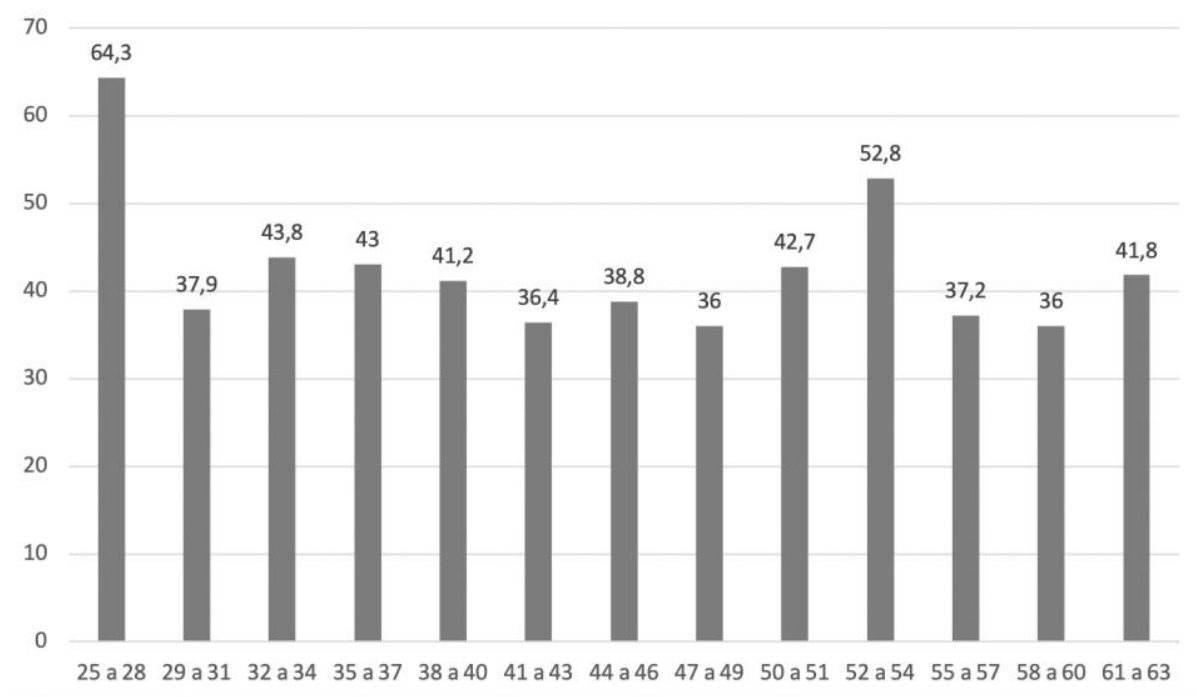

Fonte: Os autores, 2021.

O Gráfico 2 apresenta os resultados por idade que, tal como no trabalho de Wang, Myers e Sundaram (2012) sobre fluência digital, sugerem a existência de um continuum e não de uma dicotomia rígida entre os designados nativos ou sábios e os imigrantes digitais (PRENSKY, 2001, 2012), e que existem vários fatores, para além da idade ou da própria acessibilidade a ferramentas e conteúdos digitais, para explicar a questão da fluência digital. Apesar de a faixa de docentes mais novos ( 25 a 28 anos) apresentar o resultado mais elevado, temos também o grupo de docentes entre os 52 e os 54 anos de idade que apresentam o segundo valor mais alto. No gráfico 2, não se verifica a diminuição da competência digital à medida que aumenta a idade. 
Gráfico 3 - Valores médios de competências digitais docentes por área de formação

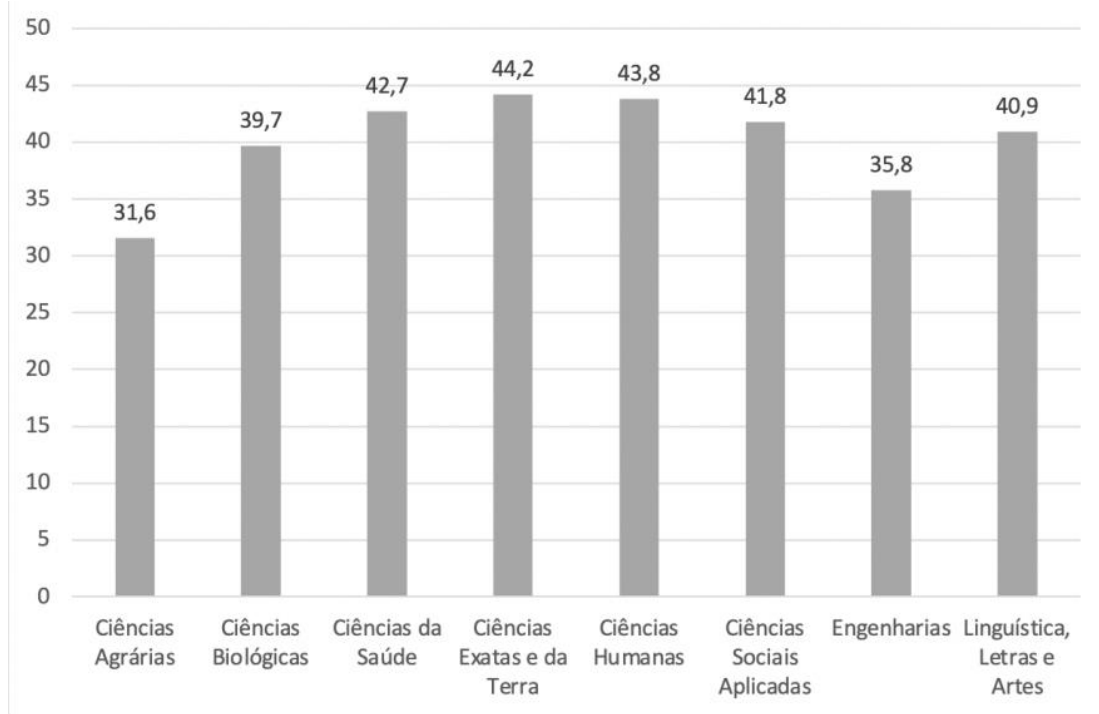

Fonte: Os autores.

Analisados os resultados médios por área de formação dos participantes, a de Ciências Agrárias é a que apresenta um valor médio mais fraco, 31, 6 pontos, situando-se no nível A2 Explorador. As restantes áreas encontram-se no nível B1 - Integrador - com valores médios relativamente próximos entre si. Ainda que muitos destes resultados estejam bastante próximos, eles acompanham também os resultados verificados no estudo de Dias-Trindade, Moreira e Ferreira (2020), em que a área das Humanidades apresentou o valor mais elevado e as áreas das engenharias estavam entre as que tiveram valores médios mais fracos.

\section{Gráfico 4 - Tempo de uso de tecnologias digitais no ensino}

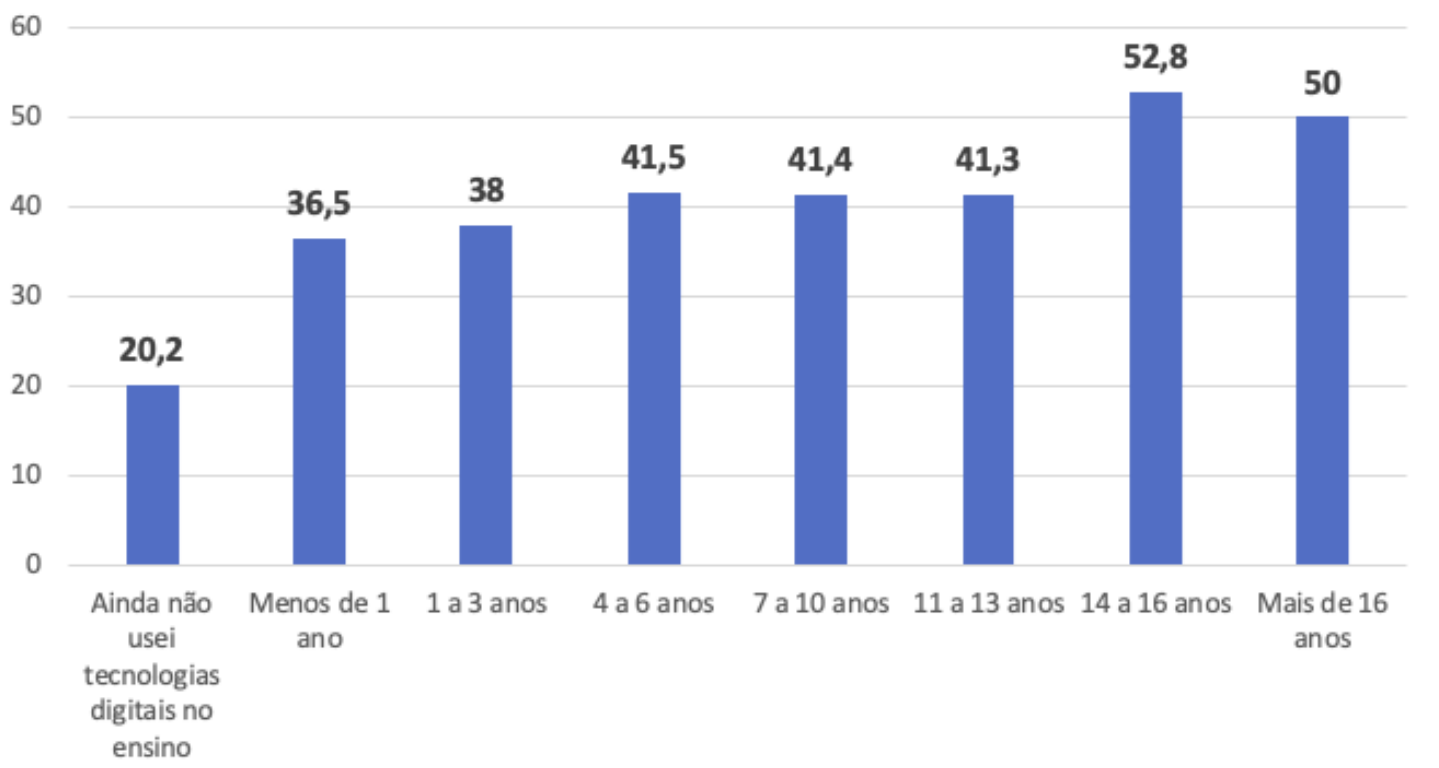

Fonte: Os autores, 2021. 
Procurando compreender um pouco mais sobre os fatores que podem contribuir para uma maior ou menor competência digital entre os docentes do Ensino Superior, foi analisado o nível de competência digital em função do tempo de uso de tecnologias digitais. Nota-se uma melhoria associada a um maior número de anos de uso das tecnologias digitais, destacando-se o fato de que os participantes que declararam não usar tecnologias digitais no ensino se encontram no nível A2, muito próximo do nível A1; entretanto, os participantes que com 14 anos de uso do digital na educação se situam já no nível B2. Se a idade do docente não afeta efetivamente a competência digital, a experiência, sim, ainda que com pequenas diferenças, parece demonstrar que o uso continuado, a experiência, são importantes para o desenvolvimento de competências digitais.

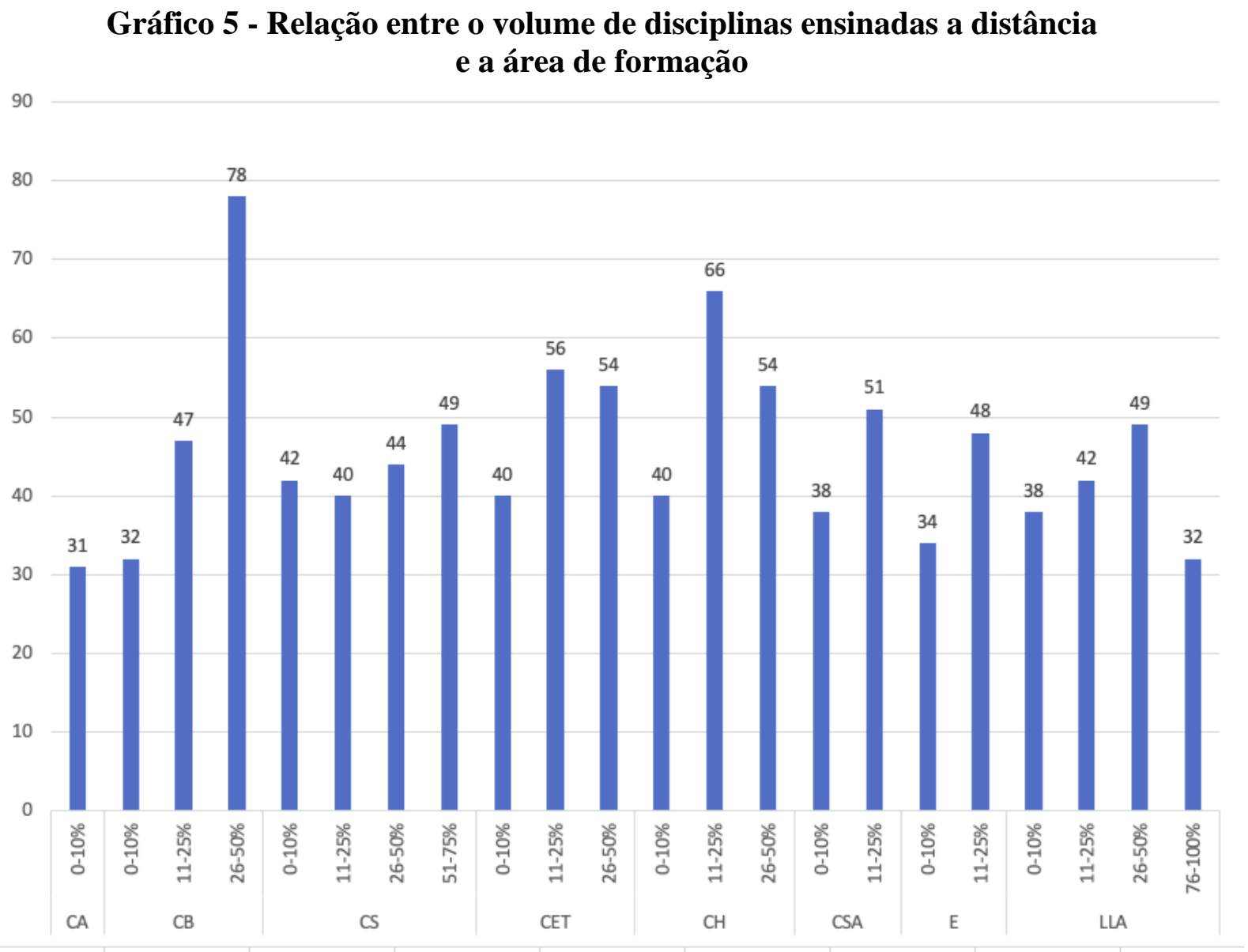

Legenda: $\mathrm{CA}=$ Ciências Agrárias; $\mathrm{CB}=\mathrm{C}$ iências Biológicas; $\mathrm{CS}=$ Ciências da Saúde; $\mathrm{CET}=$ Ciências Exatas e da Terra; $\mathrm{CH}=$ Ciências Humanas; $\mathrm{CSA}=$ Ciências Sociais Aplicadas; E= Engenharias; LLA= Linguística, Letras e Artes.

Fonte: Os autores, 2021.

Foi também analisada a relação entre o volume de disciplinas que são lecionadas na modalidade a distância $(\mathrm{EaD})$ e a área de formação dos professores (Gráfico 5). A pequena percentagem de disciplinas em $\mathrm{EaD}$ dos professores com formação em Ciências Agrárias não 
permite aferir qualquer conclusão. Porém, nas restantes áreas de formação, a maioria com até $50 \%$ (cinquenta por cento) de disciplinas lecionadas na modalidade a distância (EaD) apresenta pequenas diferenças que denotam um ligeiro aumento nas competências digitais que acompanham o maior volume de componentes curriculares ministrados a distância.

\section{Gráfico 6 - Resultados médios em relação ao volume de disciplinas ministradas a distância}

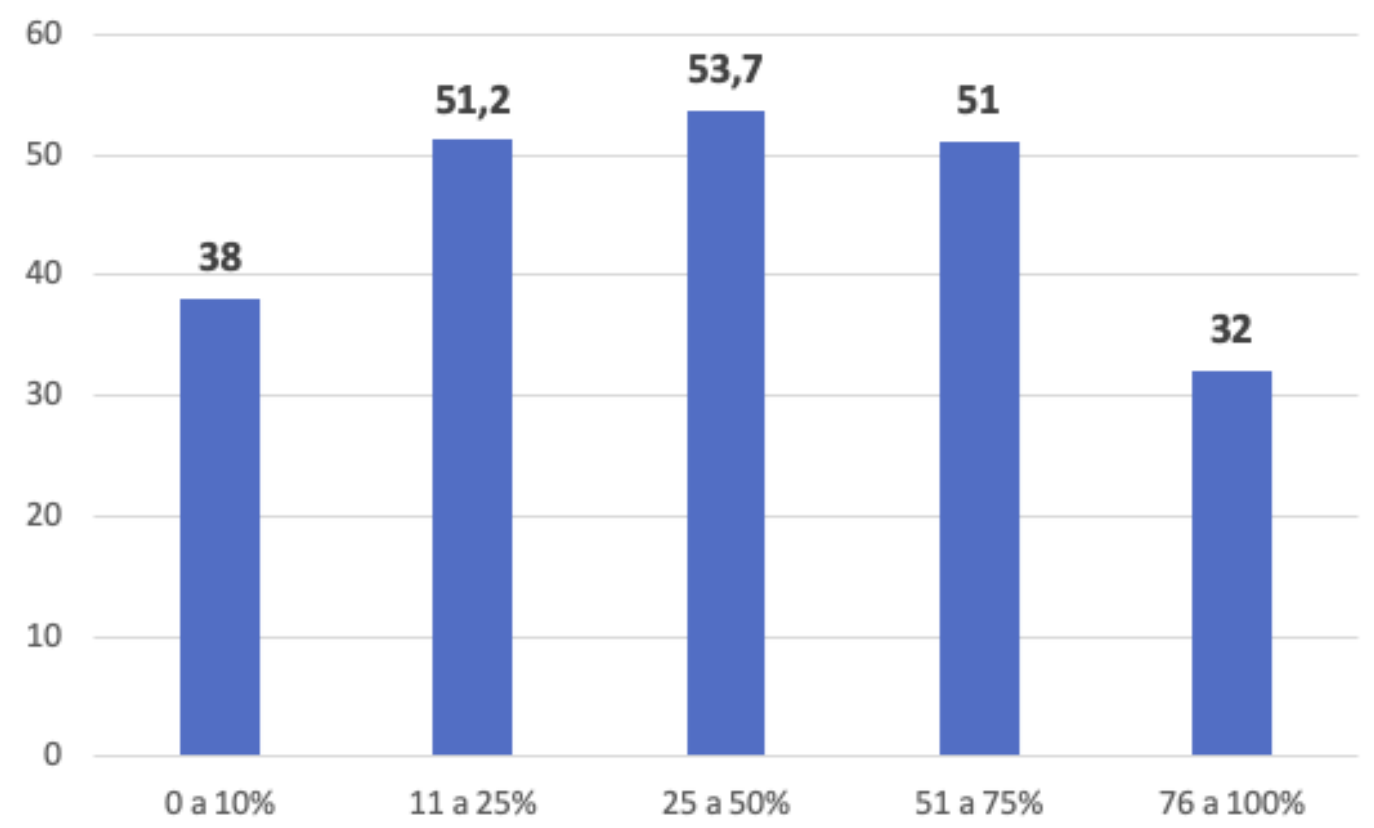

Fonte: Os autores, 2021.

Observando o Gráfico 6, e apesar de as percentagens superiores corresponderem apenas a um participante em cada uma das barras, destaca-se a mesma percepção de que quanto menor a experiência, neste caso no trabalho em $\mathrm{EaD}$, menores as competências digitais, destacandose aqueles que têm entre 0 e $10 \%$ das suas disciplinas em $\mathrm{EaD}$ com um valor mais baixo, no grupo do nível B1 - Integrador, o que acontece também com aquele que assinalou lecionar quase todas as suas disciplinas em EaD. Os restantes localizam-se no nível B2 - Especialista.

Estes resultados mostram, por um lado, que o nível de competência digital se aproxima mais da predisposição para o uso do digital, do que para idades ou áreas de atuação específicas. Ademais, esta avaliação permite o desenho de uma formação docente muito mais customizada e adaptada às reais necessidades dos professores, contemplando-se especialmente aquelas relacionadas com as maiores lacunas evidenciadas nas competências digitais dos professores avaliados, isto é, a promoção de uma práxis reflexiva com vista a melhoria contínua do processo educativo, bem como a adaptação das práticas docentes às necessidades dos discentes, quer ao 
nível da avaliação da aprendizagem quer da formação dos estudantes para o uso das tecnologias digitais, promovendo a inclusão, engajamento e, sobretudo, a autonomia dos discentes.

\section{À guisa da conclusão}

Num momento em que a educação passou emergencialmente para um formato completamente online, entende-se que é fundamental conhecer as práticas do corpo docente de cada instituição, para, naturalmente, melhor atuar.

A pandemia de COVID-19 deixou a educação no mundo inteiro restrita a ambientes digitais e o Brasil não foi exceção. Porém, apesar dos ambientes digitais educativos serem uma realidade em muitas escolas e diferentes pesquisadores apresentarem os mais variados estudos que demonstram a qualidade que podem ter esses ambientes educativos, muitos docentes apresentavam ainda resistências ao seu uso na sua práxis.

O estudo aqui apresentado encontrava-se em curso precisamente quando a Universidade Federal do Recôncavo da Bahia fechou as portas físicas em virtude do isolamento social imposto pela Covid-19. Tornou-se logo claro que o projeto assumia nova importância perante a situação pandêmica que se tem vivido desde então e que, ainda em 2021, dita a permanência do ensino online em diversas instituições de ensino superior, não só no Brasil, mas por todo o mundo.

Neste texto, apresenta-se um retrato das competências digitais docentes na UFRB que permitiu preparar e implementar nessa instituição um programa de formação continuada docente em tecnologias digitais tendo-se em conta os resultados deste questionário. É, assim, possível desenhar uma coreografia de formação que vai ao encontro das reais necessidades destes docentes, por exemplo, no que diz respeito à Área 4 do questionário - Avaliação -, que se apresentou neste estudo como uma daquelas em que os professores apresentam maiores fragilidades.

Numa situação como a vivida atualmente, em que o ensino tem de ser realizado majoritariamente por via digital, importa, de fato, reunir as ferramentas necessárias ao desenvolvimento de tarefas avaliativas adequadas a esse mesmo ensino digital.

Os resultados deste estudo confirmam que a idade e a área de formação não são determinantes para uma maior ou menor competência digital (tal como verificado já em estudos semelhantes), mas nota-se que a experiência, naturalmente, contribui para que haja resultados ligeiramente superiores entre os docentes que trabalham há mais anos com tecnologias digitais e/ou lecionam disciplinas na modalidade EaD. 
Através destas análises, sem esquecer que o valor geral médio se situa ao nível do B1 Integrador -, as leituras realizadas neste estudo permitem também compreender que, na UFRB, será fundamental que a formação docente realizada seja pensada para professores com menor experiência quer de trabalho com tecnologias digitais, quer com menor experiência em EaD.

Compreender o cenário destes docentes universitários em tempos de pandemia é fundamental para atuar estrategicamente dentro da instituição e rentabilizar os caminhos formativos que estão a ser desenhados para este conjunto de docentes. A autoavaliação realizada com a resposta a este inquérito, cujo feedback foi dado aos docentes no Conselho Superior (CONSUNI) da UFRB, permite que cada um tenha uma real noção (mesmo que baseada numa autopercepção) do caminho que deverá percorrer para evoluir do letramento para a fluência digital em cada uma das seis áreas. Isto porque a competência digital constrói-se em diferentes parâmetros, podendo o docente estar mais confortável numas áreas e menos noutras.

\section{REFERÊNCIAS}

BAUMAN, Zigmund. Modernidade líquida. Rio de Janeiro: Jorge Zahar Ed., 2001.

CARDOSO, Ariston de Lima; SANTO, Eniel do Espírito. Literacia digital: um mosaico de experiências no contexto da formação docente. In: DIAS-TRINDADE, Sara; MOREIRA, J. António; FERREIRA, António Gomes. Pedagogias digitais no ensino superior. Coimbra: CINEP/IPC, 2020.

CGI. Comitê Gestor da Internet. Centro Regional de Estudos para o Desenvolvimento para a Sociedade da Informação. TIC Domicílios 2019. São Paulo, 26 maio 2020. Disponível em: https://cetic.br/pesquisa/domicilios/indicadores/. Acesso em 22 set. 2020.

DIAS-TRINDADE, Sara; MOREIRA, José António. Avaliação das competências e fluência digitais de professores no ensino público médio e fundamental em Portugal. Revista Diálogo Educacional, Curitiba, v. 18, n. 58, p. 624-644, jul/set, 2018. Disponível em: https://periodicos. pucpr.br/index.php/dialogoeducacional/article/view/24187 Acesso em 15 ago. 2020.

DIAS-TRINDADE, Sara; FERREIRA, António Gomes. Digital teaching skills: DigCompEdu CheckIn as an evolution process from literacy to digital fluency, Icono 14 Revista Científica de Comunicación y Tecnologías Emergentes, Madri, v. 18, n. 2, p. 162-187, 2020. Disponível em: https://icono14.net/ojs/index.php/icono14/article/view/1519. Acesso em 20 set. 2020.

DIAS-TRINDADE, Sara; MOREIRA, José António; FERREIRA, António Gomes. Assessment of university teachers on their digital competences. QWERTY, Open and Interdisciplinary Journal of Technology, Culture and Education, v. 15, n. 1, p. 50-69, 2020. Disponível em http://www.ckbg.org/qwerty/index.php/qwerty/article/view/341/296 Acesso em 2 ago. 2020. 
EUROPEAN PARLIAMENT AND COUNCIL. Recommendation of the European Parliament and the Council of 18 December 2006 on key competences for lifelong learning. Official Journal of the European Union, L394, 2006.

FERRARI, Anusca. Digital Competence in Practice: An Analysis of Frameworks. JRC Technical Reports. Luxembourg: Publications Office of the European Union, 2012.

FIGUEIREDO, António Dias. Por uma escola com futuro... para além do digital. Nova Ágora - Revista, n. 5, p. 19-21, set. 2016. Disponível em: https://www.researchgate.net/ publication/309124131/download. Acesso em: 25 set. 2020.

FROM, Jorgen. Pedagogical digital competence: between values, knowledge and skills. Higher Education Studies, Ontario, v. 7, n. 2, p. 43-50, 2017.

ILOMÄKI, Liisa; PAAVOLA, Sami; LAKKALA, Minna; KANTOSALO, Anna. Digital competence: an emergent boundary concept for policy and educational research. Education and Information Technologies, v. 21, n. 3, p. 655-679, 2016.

KOEHLER, Mattew J.; MISHRA, Punya.; CAIN, William. What Is Technological Pedagogical Content Knowledge (TPACK)? Journal of Education, v. 193, n. 3, p. 13-19, 2013. Disponível em: https://www.researchgate.net/publication/321505356_What_is_ Technological_Pedagogical_Content_Knowledge_TPACK. Acesso em: 20 set. 2020.

LE BOTERF, Guy. Construir as Competências Individuais e Colectivas. Porto: Asa, 2005.

THE NATIONAL Institute of Educational Technologies and Teacher Training (INTEF). Common Digital Competence Framework for Teachers. 2017. Disponível em: https://aprende.intef.es/sites/default/files/2018-05/2017_1024-Common-Digital-CompetenceFramework-For-Teachers.pdf. Acesso em: 22 set. 2020.

ONU. Objetivos de Desenvolvimento Sustentável. Set. 2015. Disponível em: https://brasil.un.org/pt-br/sdgs. Acesso em: 20 set. 2020.

OTA, Marcos Andrei; DIAS-TRINDADE, Sara. Ambientes digitais de aprendizagem e competências digitais: conhecer o presente para agir num futuro pós-COVID. Revista Interfaces Científicas - Educação, Aracaju, v. 10, n. 1, p. 211-226, 2020. DOI: 10.17564/2316-3828.2020v10n1p211-226.

PRENSKY, Marc. Digital natives, digital immigrants. On the Horizon. MCB University Press, v. 5, n. 9, p. 1-6, 2001.

PRENSKY, Marc. From Digital natives to digital wisdom: hopeful essays for 21st century learning. Corwin Press, 2012. Disponível em https://www.doi.org/10.4135/9781483387765 Acesso em 10 jan. 2021.

RANIERI, Maria.; BRUNI, Isabella.; XIVRY, Anne-Claire Orban De Xivry. Teachers ' Professional Development on Digital and Media Literacy: Findings and recommendations from a European project. REM - Research on Education and Media. v. 10, n. 2, p. 10-19, 2017. 


\section{SOBRE OS AUTORES:}

\section{Sara Dias-Trindade}

Doutora em História - Didática, Universidade de Coimbra; Universidade de Coimbra, Centro de Estudos Interdisciplinares (CEIS20), Faculdade de Letras (DHEEAA); membro da equipa de coordenação do CEIS20. E-mail: sara.trindade@uc.pt

(iD) https://orcid.org/0000-0002-5927-3957

\section{Eniel do Espírito Santo}

Doutor em Educação, UDE, Uruguai, Pós-doutorado em Educação, FCU, EUA; Universidade Federal do Recôncavo da Bahia, UFRB - Brasil; Programa de Pós-Graduação em Educação e Tecnologias Digitais/UFRB; Vice-Líder do Grupo de Pesquisa em Tecnologias Educacionais, Robótica e Física - GTERF. E-mail: eniel@ufrb.edu.br (iD) https://orcid.org/0000-0003-0589-1298 